\title{
Systematic Review of Randomized Controlled Trials: Fiber Supplements for Abdominal Pain-Related Functional Gastrointestinal Disorders in Childhood
}

\author{
Andrea Horvath Piotr Dziechciarz Hania Szajewska \\ Department of Pediatrics, Medical University of Warsaw, Warsaw, Poland
}

\section{Key Words}

Chronic abdominal pain $\cdot$ Fiber $\cdot$ Microbiota $\cdot$ Prebiotics . Randomized controlled trials

\begin{abstract}
Background: A lack of safe and reliable treatments for abdominal pain-related functional gastrointestinal disorders (FGIDs) has prompted interest in new therapies. Aim: To systematically evaluate the effect of dietary fibers for treating abdominal pain-related FGIDs in children. Methods: In December 2011, MEDLINE, EMBASE and the Cochrane Library were searched for randomized controlled trials (RCTs) evaluating fiber supplementation in children with FGIDs. Results: Only 3 RCTs were identified, which enrolled a total of 167 children and adolescents (5-17 years old) with recurrent abdominal pain. Only 1 study used the Rome III criteria. Patients were supplemented with different dietary fiber types for 4-6 weeks. The use of dietary fibers did not influence the proportion of responders to treatment, and improvement did not occur in reported clinically relevant outcomes such as no pain or a significant decrease in pain intensity (risk ratio $1.17,95 \%$ confidence interval $0.75-1.81)$. Conclusion: There is no evidence that supplementation with fiber as a dietary manipulation may be useful for treating children with FGIDs. However, one should not overlook the fact that the main limitation for recommendation of the routine fiber use in clinical practice derives from the weak quality and paucity of available studies.

Copyright $\odot 2012$ S. Karger AG, Basel
\end{abstract}

\section{Introduction}

Abdominal pain-related functional gastrointestinal disorders (FGIDs) are common in the pediatric population and affect between 13 and $38 \%$ of children and adolescents [1]. No specific serologic markers or laboratory findings exist for functional abdominal disorders, whose evaluation and classification are primarily based on clinical signs. According to the Rome III criteria, abdominal painrelated FGIDs in children are categorized as functional dyspepsia (FD), irritable bowel syndrome (IBS), abdominal migraine and functional abdominal pain (FAP) $[2,3]$.

Due to the complex and unexplained pathophysiology of abdominal pain-related FGIDs, their management remains difficult. The selection of the type of treatment to be administered to patients with FGIDs is further complicated by the fact that while individuals may exhibit similar troublesome gastrointestinal symptoms, the underlying cause in each case may differ [4]. The chronic relapsing nature of these conditions paired with the lack of effective and safe options for treatment have a negative impact on the patients and their families regarding all aspects of their lives [1]. As a result of these factors, the management of FGIDs tends to focus on the amelioration of symptoms rather than on the modification of the course of the disease or on its cure.

First-line strategies traditionally developed in the treatment of FGID patients include dietary modifications and lifestyle changes [5]. It is worth noting that in a recent

\section{KARGER}

Fax +4161306 1234

E-Mail karger@karger.ch

www.karger.com (c) 2012 S. Karger AG, Basel

0250-6807/12/0612-0095\$38.00/0

Accessible online at:

www.karger.com/anm
Andrea Horvath, MD

Department of Pediatrics

Medical University of Warsaw

Dzialdowska 1, PL-01-184 Warsaw (Poland)

Tel. +48 2245233 09, E-Mail andrea.hania@gmail.com 
survey of $>1,200$ adults with IBS, $63 \%$ of sufferers were interested in obtaining information about which foods to avoid, and $58 \%$ believed that higher fiber intake would help them relieve their symptoms [6].

Prior to our study, 3 meta-analyses and 5 systematic reviews evaluated the effects of prebiotics for the treatment of IBS primarily in the adult population, with each of the studies reaching slightly different conclusions [714]. For treatment of the adult population, the American College of Gastroenterology recently concluded that ispaghula husk, despite the equivocal results, is moderately effective in relieving symptoms and can be given a conditional recommendation. In contrast, wheat bran or corn bran are not sufficiently effective in relieving global symptoms of IBS and should not be recommended for routine use [15].

In regard to the pediatric population, a Cochrane systematic review (search date: November 2006) concluded that there is no evidence that dietary fiber supplementation is effective in the management of recurrent abdominal pain [9]. However, Huertas-Ceballos et al. [9] identified only 2 studies that employed varying methodological quality, used different types of fiber, and enrolled a heterogeneous population of children in the analysis which supported their conclusion $[16,17]$. Nevertheless, many clinicians routinely recommend the use of bulking agents or dietary fiber to stimulate regular bowel movements and to improve symptoms associated with FGIDs [1]. With the current systematic review, we aimed to update and synthesize the available clinical trial evidence of the likely effects of dietary fiber in children affected by abdominal pain-related FGID.

\section{Methods}

Criteria for Considering Studies for this Review

All relevant randomized controlled trials (RCTs) that compared the effects of dietary fiber supplementation with the effects of placebo or no supplementation for treating abdominal painrelated FGIDs in children were considered for this review.

Search Methods for Identification of Studies

The Cochrane Central Register of Controlled Trials (CENTRAL, the Cochrane Library, issues 4, 2011), MEDLINE (19662011) and EMBASE (1980-2011) were systematically searched up to December 2011. The reference lists of identified studies and key review articles, including previously published reviews, were also searched for all studies that assessed the effects of dietary fiber supplementation on abdominal pain-related FGIDs in children. No language restrictions were imposed. Letters to the editor, abstracts and proceedings from scientific meetings were excluded a priori from the analysis. The search strategy included the use of a validated filter for identifying RCTs, which was combined with a topic-specific strategy using the following PubMed MeSH terms: (fiber OR fibre OR prebiotic* OR oligosaccharide OR fructo-oligosaccharides OR galacto-oligosaccharide OR oligo) and (functional abdominal pain OR irritable bowel syndrome OR functional dyspepsia OR abdominal pain-related disorders OR Rome criteria). Two of the reviewers (P.D. and A.H.) searched the databases independently and screened bibliographies of retrieved studies and recent review articles. The primary outcome measure was the rate of responders to the treatment (defined as a clinically meaningful improvement in gastrointestinal symptoms, such as no pain or a decrease in pain intensity/frequency). The secondary outcome measures were the frequency and intensity/severity of abdominal pain reported by patients or their caregivers and adverse events.

\section{Selection of Studies}

We excluded studies if the title and abstract were not relevant; however, we obtained complete papers for all potentially relevant studies if the abstract contained insufficient information for inclusion of the study. All issues of disagreement were discussed by the researchers in order to achieve a consensus.

\section{Data Extraction and Management}

Data from each study were extracted by all of the reviewers using standardized data extraction forms. After extraction, all data were compared in order to minimize the possibility of errors.

\section{Assessment of Risk of Bias in the Studies}

The reviewers independently assessed the risk of bias in the studies that met the inclusion criteria, but without being blinded to the authors or journals. We used the Cochrane Collaboration tool for assessing risk of bias, which includes the following criteria: adequacy of sequence generation, allocation concealment, and blinding of participants, personnel and outcome assessors. Incomplete outcome data are addressed. In all cases, an answer of 'yes' indicates a low risk of bias and an answer of 'no' indicates a high risk of bias.

\section{Measures of Treatment Effect}

The dichotomous outcomes, results for individual studies and pooled statistics are reported as the risk ratio (RR) between the experimental and control groups with $95 \%$ confidence intervals (CI). The standardized mean difference between the treatment and control groups was selected to represent the difference in continuous outcomes (with 95\% CI). For all outcomes, subgroup analyses based on the diagnosis (i.e. IBS, FAP and FD) were performed.

\section{Dealing with Missing Data}

We assessed pooled data using available case analysis, i.e. an analysis in which data are analyzed for every participant for whom the outcome was obtained rather than intention-to-treat analysis with imputation [18].

\section{Assessment of Heterogeneity}

Heterogeneity was quantified by $\chi^{2}$ and $\mathrm{I}^{2}$, which can be interpreted as the percentage of the total variation between studies that is attributable to heterogeneity rather than to chance. A value of $0 \%$ indicates no observed heterogeneity, while larger values show increasing heterogeneity. If heterogeneity was not revealed, we 
present only results of the fixed effect model. If there was substantial heterogeneity $(>50 \%)$, all analyses were based on the random effect model on the condition that it was still considered appropriate to pool the data.

Data Synthesis (Statistical Methods)

The data were analyzed using the computer program Review Manager (RevMan; version 5.1.6; Copenhagen, Nordic Cochrane Center, Cochrane Collaboration, 2010).

\section{Results}

\section{Studies Included}

The literature search yielded 58 articles, of which 10 were reviewed in acceptable, full text (fig. 1) [9, 16, 17, 19-25]. Of these studies, only 3 RCTs met the inclusion criteria $[16,17,25]$. One was published in Danish (Christensen [16]), and the other 2 were published in English (Feldman et al. [17] and Horvath et al. [25]). These RCTs studied a total of 167 patients. Table 1 summarizes the characteristics of the included studies. The characteristics of the excluded trials, with reasons for exclusion provided, are available upon request. All 3 RCTs enrolled children and adolescents (5-17 years of age) with recurrent abdominal pain; however, only 1 study differentiated between the subtypes of FGIDs according to the Rome III criteria: IBS, FAP and FD [25]. The sample size ranged from 31 to 84 participants. In all of the studies, a different type of dietary fiber was compared with placebo. In 2 studies, children received a diet supplemented with fiber (crushed crispbread [16] or cookies [17]). In one study, fiber was administered individually in sachets, as a soluble powder [25]. The supplementation period lasted for 4 [25] or 6 weeks $[16,17]$. Two RCTs were performed in European countries, namely Poland [25] and Denmark [16], and 1 RCT was conducted in Canada [17].

\section{Risk of Bias in the 3 Trials}

Table 2 shows the results of the methodological quality assessment. Two of the studies had good methodological quality $[17,25]$. The main limitation of the study by Christensen et al. [16] was that outcome data were incomplete ( $>20 \%$ were lost to follow-up). The 2 others were rated at low risk for incomplete outcome data $[17,25]$.

\section{Heterogeneity}

Significant heterogeneity $\left(\mathrm{I}^{2} \geq 50 \%\right)$ was found for the overall study population for the improvement defined by the authors as changes in the frequency of pain $\left(\chi^{2}=3.33\right.$, $\mathrm{p}=0.19, \mathrm{I}^{2}=40 \%$ ). In 2 studies (Feldman et al. [17] and

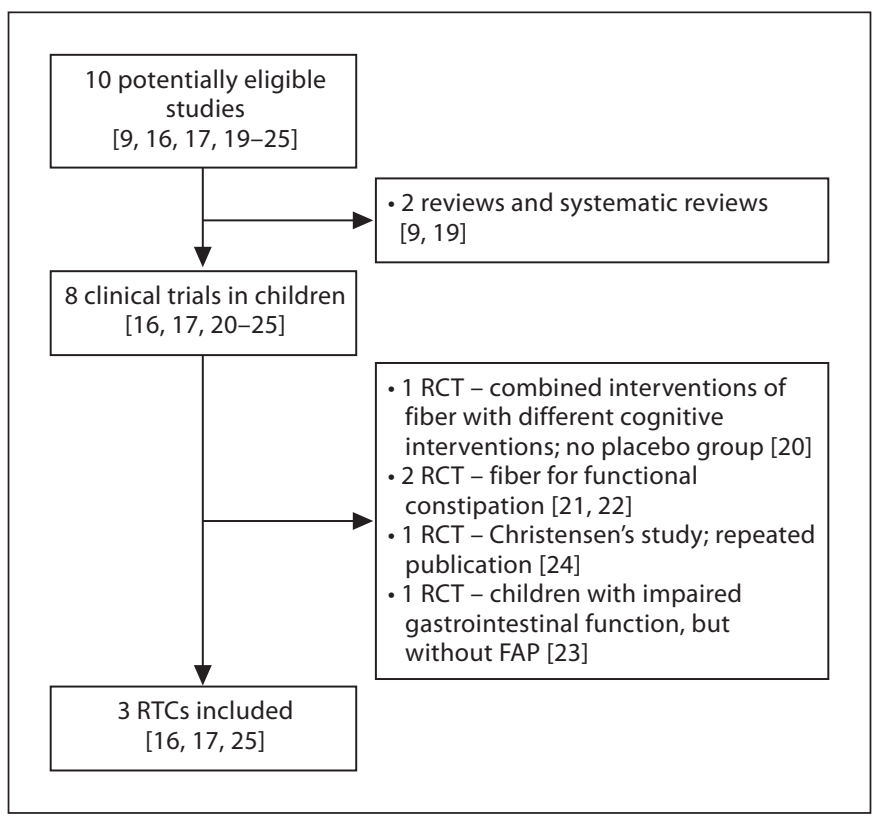

Fig. 1. Identification process for eligible trials.

Horvath et al. [25]), the observed statistical heterogeneity was not judged to be clinically relevant (i.e. the studies consistently reported results of the same analogous results with clinically insignificant differences between them) $[17,25]$. However, the study by Christensen et al. [16] did adequately determine heterogeneity.

\section{Effects of Intervention}

\section{Primary Outcome}

All 3 RCTs of dietary fiber supplements reported data that could be analyzed using the criterion of improvement versus no improvement, based on the frequency or intensity of the abdominal pain $[16,17,25]$.

Patients in the fiber group were more likely to experience 'no pain' and/or 'satisfactory improvement' (52\%) than patients in the placebo group (43\%); however, the difference was not statistically significant (RR 1.17, 95\% CI 0.75-1.81; fig. 2).

The planned subgroup analysis for insoluble compared to soluble fiber administration could not be performed because of the very small size of the group and the high heterogeneity of the study population.

\section{Secondary Outcomes}

Feldman et al. [17] and Horvath et al. [25] assessed changes in the intensity of pain, but in these studies numerical results were not reported. The former reported 
Table 1. Characteristics of the studies included

\begin{tabular}{|c|c|c|c|c|c|}
\hline Study & Participants & Diagnostic criteria & Fiber & Comparison & Outcomes \\
\hline $\begin{array}{l}\text { Christensen } \\
{[16]} \\
1982\end{array}$ & $\begin{array}{l}\text { children and } \\
\text { adolescents } \\
(3-15 \text { years })\end{array}$ & $\begin{array}{l}\text { RAP (at least } \\
10 \text { episodes of } \\
\text { abdominal pain } \\
\text { during the last } \\
6 \text { weeks); recruited } \\
\text { from hospital }\end{array}$ & $\begin{array}{l}\text { ispaghula husk } \\
\text { (Vi-Siblin } 5 \mathrm{ml} / \text { twice } \\
\text { daily; crushed } \\
\text { crispbread with } 66 \% \\
\text { fiber) during a } 6 \text {-week } \\
\text { period }\end{array}$ & $\begin{array}{l}\text { placebo } \\
\text { (crushed } \\
\text { crispbread with } \\
\sim 2 \% \text { fiber) }\end{array}$ & $\begin{array}{l}\text { change in the abdominal pain } \\
\text { frequency score } \\
\text { improvement: }<10 \text { episodes of } \\
\text { pain during the study period }\end{array}$ \\
\hline $\begin{array}{l}\text { Horvath } \\
\text { et al. [25] } \\
2012\end{array}$ & $\begin{array}{l}\text { children and } \\
\text { adolescents } \\
\text { ( } 6-16 \text { years })\end{array}$ & $\begin{array}{l}\text { Rome III criteria } \\
\text { for IBS, FAP and } \\
\text { FD }\end{array}$ & $\begin{array}{l}\text { glucomannan } \\
\text { (Dicoman Junior, Vitis } \\
\text { Pharma at a dosage of } \\
2.52 \mathrm{~g} \text { /day; } 1 \text { sachet of } \\
1.26 \mathrm{~g} 2 \text { times a day) } \\
\text { during a } 4 \text {-week period }\end{array}$ & $\begin{array}{l}\text { placebo } \\
\text { (maltodextrin) }\end{array}$ & $\begin{array}{l}\text { no pain } \\
\text { improvement: no pain or a } \\
\text { decrease } \geq 2 / 6 \text { points on the } \\
\text { Faces Pain Scale Revised } \\
\text { secondary outcomes: change } \\
\text { in the frequencies of } \\
\text { gastrointestinal symptoms, } \\
\text { daily activities, school } \\
\text { absenteeism, rescue therapy }\end{array}$ \\
\hline
\end{tabular}

RAP $=$ Recurrent abdominal pain

Table 2. Methodological quality summary: review authors' judgments about each methodological quality item for each RCT included

\begin{tabular}{lllll}
\hline Study ID & $\begin{array}{l}\text { Adequate } \\
\text { sequence } \\
\text { generation }\end{array}$ & $\begin{array}{l}\text { Allocation } \\
\text { concealment }\end{array}$ & Blinding & $\begin{array}{l}\text { Incomplete } \\
\text { data } \\
\text { addressed }\end{array}$ \\
\hline $\begin{array}{l}\text { Christensen } \\
\text { [16], 1982 }\end{array}$ & yes & unclear & yes & $\begin{array}{l}\text { no, 31/40 } \\
(78 \%)\end{array}$ \\
\hline $\begin{array}{l}\text { Feldman } \\
\text { et al. [17], 1985 }\end{array}$ & yes & yes & yes & $\begin{array}{l}\text { yes, 52/52 } \\
(100 \%)\end{array}$ \\
\hline $\begin{array}{l}\text { Horvath } \\
\text { et al. [25], 2012 }\end{array}$ & yes & yes & yes & $\begin{array}{l}\text { yes, 84/89 } \\
(94 \%)\end{array}$ \\
\hline
\end{tabular}

In all cases, an answer of 'yes' indicates a low risk of bias; an answer of ' $n o$ ' indicates a high risk of bias.

that children included in the treatment group experienced less severe pain, but that the differences between the treatment and placebo groups 'were not significant' [17]. In the study by Horvath et al. [25], no specific data were provided [25].
Moreover, Horvath et al. [25] reported no significant differences between the glucomannan group and the placebo group in the secondary outcome measures, such as the subjective assessment of gastrointestinal symptoms, i.e., abdominal cramps, abdominal bloating/gassiness, the number of episodes of nausea or vomiting, or change in stool consistency [25].

\section{Adverse Effects}

Only 2 studies assessed the adverse effects of fiber supplementation [17, 25]. In the study by Feldman et al. [17], the number of children who experienced gas or diarrhea as a side effect was small in both groups. They concluded that the differences in the incidence rates of side effects between both groups were insignificant. In the study by Horvath et al. [25], fiber was well tolerated and no adverse effects were reported.

\section{Discussion}

\section{Summary of the Main Results}

In this systematic review, evidence regarding the effectiveness of dietary fiber supplementation for the treat- 


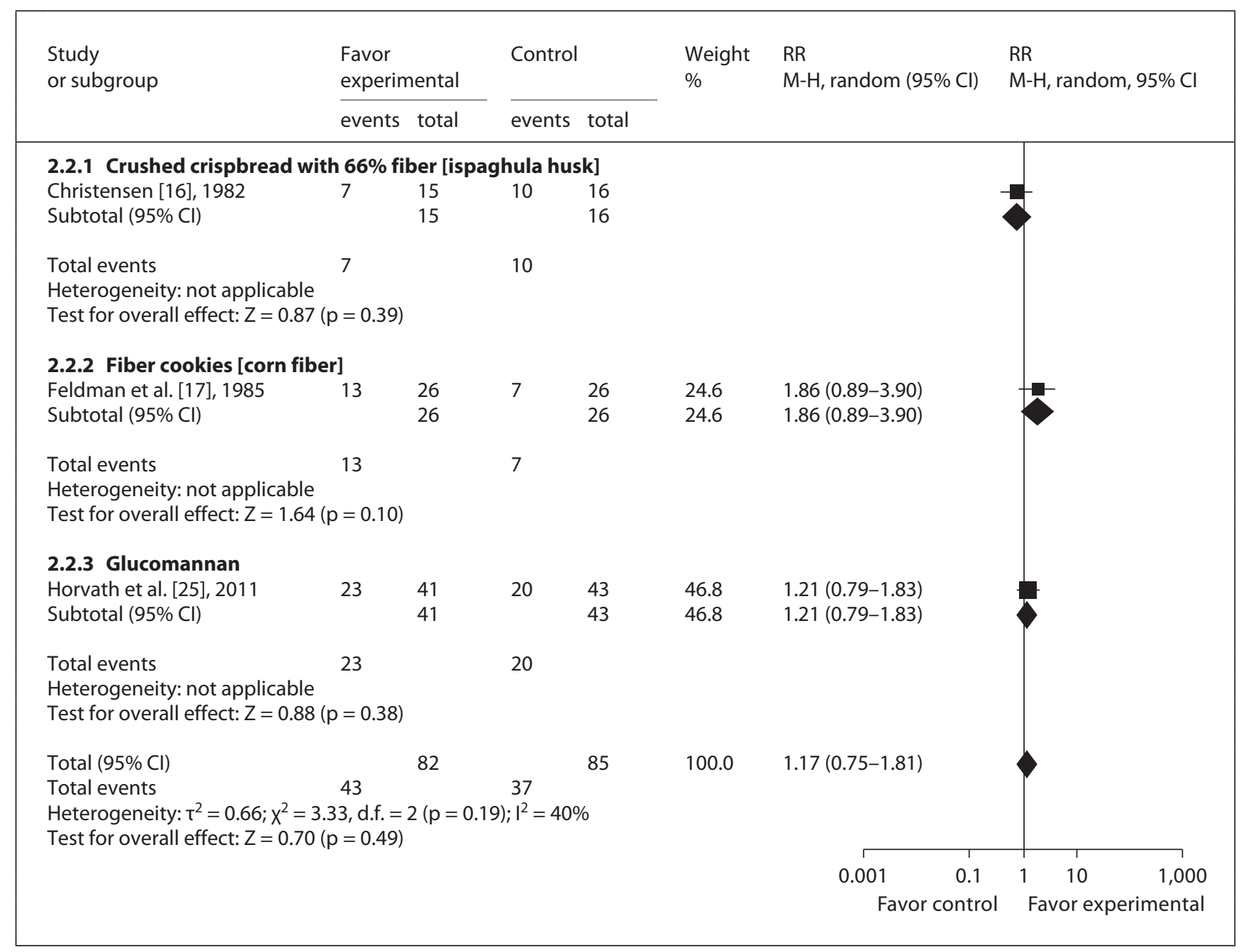

Fig. 2. Effect of fiber on FGID improvement.

ment of diagnosed abdominal pain-related FGIDs in children was evaluated and summarized. The obtained results indicate very limited and unsatisfactory evidence to support the role of fiber supplementation for FGIDs symptoms in children.

In the 3 studies identified, we found that the use of dietary fiber did not influence the proportion of responders to the treatment and improvement did not occur in reported clinically relevant outcomes such as no pain or a significant decrease in pain intensity.

Furthermore, the heterogeneity of the population consisting of 3 small subgroups of patients with IBS, FAP or FD was so high and the numbers of children in the subgroups were so limited, that subgroup analyses for the different fiber types (soluble vs. insoluble) could not be performed.

Fiber and Abdominal Pain-Related Functional Disorders
For the same reason, we did not present the results of the subgroup analyses involving patients with IBS, FAP and FD in this systematic review. While a more homogenous group would have been preferable, in clinical practice the division between specific diagnoses, particularly between FD, IBS and FAP, is not always clear-cut and cannot be achieved in all children.

Dietary fiber was well tolerated, and no adverse effects or insignificant differences were reported.

\section{How the Intervention Might Work}

The unclear pathophysiology of FGIDs on the one hand and the lack of effective treatment for FGIDs on the other have prompted interest in new and safe therapeutic options, including dietary interventions for example. Dietary fiber supplements comprise a heterogeneous group

Ann Nutr Metab 2012;61:95-101 
of complex carbohydrates that are resistant to hydrolysis during digestion. Various commercially available fiber supplements include soluble fibers, such as psyllium, ispaghula husk, partially hydrolyzed guar gum, fructooligosaccharide, oligosaccharide, calcium polycarbophilas as well as insoluble fibers, such as bran (wheat and corn) and ground flaxseed [26].

While the exact processes by which prebiotics may exert their actions in patients with FGIDs are not fully understood, several mechanisms have been suggested. These include:

- changes in the intestinal microbiota by selective stimulation of the growth of potentially protective bacteria (bifidobacteria and, in part, also lactobacilli) and simultaneous inhibition of potentially pathogenic microorganisms [1,27];

- changes in the composition of stool and gas [1, 28, 29];

- stabilization of the intestinal environment by reduction in the $\mathrm{pH}$ and release of short-chain organic acids $[1,30]$, and

- downregulation of the local proinflammatory response and control of intestinal motor functions [1, 31].

Dietary fiber consumption has remained low in many populations, especially in children. The American Academy of Pediatrics recommends a daily dietary fiber intake for children of $0.5 \mathrm{~g} / \mathrm{kg}$ body weight, up to $35 \mathrm{~g} /$ day [32]. Williams et al. [33] proposed a minimum daily fiber intake equivalent to age in years plus $5 \mathrm{~g}$ /day for children older than 2 years.

Knowledge of the precise data on the daily fiber intake in this review would be useful. However, one of the major drawbacks of the studies included is that data concerning daily fiber intake from food are missing, which make the results of meta-analysis very difficult to interpret.

\section{Overall Completeness and Applicability of Evidence}

Our search included 3 major databases, with no language restrictions. The searching, extraction of the data and assessment of the validity of the studies were performed independently by 2 reviewers to decrease the likelihood of reviewer error or bias. Nonetheless, we cannot fully exclude the possibility of publication bias, which is a significant threat to the validity of systematic reviews and is difficult to combat except through the registration of all RCTs. We did not perform a statistical test for the detection of publication bias, because we are aware that these tests have very low power in the meta-analysis of only a few trials [18].

\section{Quality of Evidence}

Any systematic review is only as good as the constituent studies. In general, 2 of the 3 included RCTs employed sound methodology with adequate randomization, allocation concealment, blinding and follow-up. One potential limitation of the review is that it included a small number of trials with small sample sizes, particularly when subgroups of patients with specific diagnoses were evaluated. Nevertheless, to increase power is one of the reasons why a meta-analysis is performed within a systematic review [34].

One of the major limitations of our review is that it focuses on the different fiber sources. Fiber supplementation is not a homogeneous intervention. Therefore, pooling data from different fiber types, doses and durations of administration may result in misleading conclusions.

In all of the included trials, the fiber intervention lasted not less than 4 weeks, which is in line with the Rome Foundation document providing guidance for the design of treatment trials in patients with FGIDs [34]. However, there is a lack of data on the long-term effects of fiber supplementation for abdominal pain-related FGIDs.

\section{Implications for Practice}

The results of our systematic review do not provide preliminary evidence that supplementation with fiber as a dietary manipulation may be useful for treating children with abdominal pain-related FGIDs. In effect, at present, any recommendation for the routine use of fiber in clinical practice or in families is unsupportable.

\section{Implications for Research}

Fiber seems to be a good candidate for a large multicenter trial in children with abdominal pain-related FGIDs, properly categorized into IBS, FAP and FD subgroups. Due to the relapsing nature of the disease and the fact that effects of fiber may endure only for as long as the supplement is administered, the treatment duration and follow-up period after cessation of treatment should allow for the adequate assessment of short- and longterm effects of fiber. There is also a strong need for a standardized, properly validated outcome assessments scale. Given the fact that the exact mechanism of action of fiber is not known, there still exists a pressing need for further experimental studies into fiber properties and function. 


\section{Acknowledgment}

This study was funded in full by the Medical University of Warsaw.

\section{Disclosure Statement}

The authors have no conflict of interest to declare.

\section{References}

1 Chiou E, Nurko S: Management of functional abdominal pain and irritable bowel syndrome in children and adolescents. Expert Rev Gastroenterol Hepatol 2010;4:293-304.

$\checkmark 2$ Hyman PE, Milla PJ, Benninga MA, Davidson GP, Fleisher DF, Taminiau J: Childhood functional gastrointestinal disorders: neonate/toddler. Gastroenterology 2006;130: 1519-1526.

-3 Rasquin A, Di Lorenzo C, Forbes D, Guiraldes E, Hyams JS, Staiano A, Walker LS: Childhood functional gastrointestinal disorders: child/adolescent. Gastroenterology 2006;130:1527-1537.

4 Malone MA: Irritable bowel syndrome. Prim Care 2011;38:433-447.

$>5$ Sainsbury A, Ford AC: Treatment of irritable bowel syndrome: beyond fiber and antispasmodic agents. Therap Adv Gastroenterol 2011;4:115-127.

-6 Halpert A, Dalton CB, Palsson O, Morris C, $\mathrm{Hu} \mathrm{Y}$, Bangdiwala S, Hankins J, Norton N, Drossman D: What patients know about irritable bowel syndrome (IBS) and what they would like to know. National Survey on Patient Educational Needs in IBS and development and validation of the Patient Educational Needs Questionnaire (PEQ). Am J Gastroenterol 2007;102:1972-1982.

-7 Ford AC, Talley NJ, Spiegel BM, Foxx-Orenstein AE, Schiller L, Quigley EM, Moayyedi P: Effect of fibre, antispasmodics, and peppermint oil in the treatment of irritable bowel syndrome: systematic review and metaanalysis. BMJ 2008;337:a2313.

-8 Lesbros-Pantoflickova D, Michetti P, Fried M, Beglinger C, Blum AL: Meta-analysis: the treatment of irritable bowel syndrome. Aliment Pharmacol Ther 2004;20:1253-1269.

$>9$ Huertas-Ceballos AA, Logan S, Bennett C, Macarthur C: Dietary interventions for recurrent abdominal pain (RAP) and irritable bowel syndrome (IBS) in childhood. Cochrane Database Syst Rev 2009;1:CD003019.

$\checkmark 10$ Chouinard LE: The role of psyllium fibre supplementation in treating irritable bowel syndrome. Can J Diet Pract Res 2011;72: e107-e114.

-11 Brandt LJ, Bjorkman D, Fennerty MB, Locke GR, Olden K, Peterson W, Quigley E, Schoenfeld P, Schuster M, Talley N: Systematic review on the management of irritable bowel syndrome in North America. Am J Gastroenterol 2002;97:S7-S26.
12 Bijkerk CJ, Muris JW, Knottnerus JA, Hoes AW, de Wit NJ: Randomized patients in IBS research had different disease characteristics compared to eligible and recruited patients. J Clin Epidemiol 2008;61:1176-1181.

13 Ruepert L, Quartero AO, de Wit NJ, van der Heijden GJ, Rubin G, Muris JW: Bulking agents, antispasmodics and antidepressants for the treatment of irritable bowel syndrome. Cochrane Database Syst Rev 2011; 8:CD003460.

14 Jailwala J, Imperiale TF, Kroenke K: Pharmacologic treatment of the irritable bowel syndrome: a systematic review of randomized, controlled trials. Ann Intern Med 2000; 133:136-147.

15 American College of Gastroenterology Task Force on Irritable Bowel Syndrome, Brandt LJ, Chey WD, Foxx-Orenstein AE, Schiller LR, Schoenfeld PS, Spiegel BM, Talley NJ, Quigley EM: An evidence-based position statement on the management of irritable bowel syndrome. Am J Gastroenterol 2009; 104:S1-S35.

16 Christensen MF: Do bulk preparations help in cases of recurrent abdominal pain in children? A controlled study (in Danish). Ugeskr Laeger 1982;144:714-715.

-17 Feldman W, McGrath P, Hodgson C, Ritter $\mathrm{H}$, Shipman RT: The use of dietary fiber in the management of simple, childhood, idiopathic, recurrent, abdominal pain. Results in a prospective, double-blind, randomized, controlled trial. Am J Dis Child 1985;139: 1216-1218.

18 Higgins JPT, Deeks JJ: Special topics in statistics; in Higgins JPT, Green S (eds): Cochrane Handbook for Systematic Reviews of Interventions, version 5.0.1.Cochrane Collaboration. Chichester, Wiley, 2008.

19 Weydert JA, Ball TM, Davis MF: Systematic review of treatments for recurrent abdominal pain. Pediatrics 2003;111:e1-e11.

20 Humphreys PA, Gevirtz RN: Treatment of recurrent abdominal pain: components analysis of four treatment protocols. J Pediatr Gastroenterol Nutr 2000;31:47-51.

21 Kokke FT, Scholtens PA, Alles MS, Decates TS, Fiselier TJ, Tolboom JJ, Kimpen JL, Benninga MA: A dietary fiber mixture versus lactulose in the treatment of childhood constipation: a double-blind randomized controlled trial. J Pediatr Gastroenterol Nutr 2008;47:592-597.
22 Üstündağ G, Kuloğlu Z, Kirbaș N, Kansu A: Can partially hydrolyzed guar gum be an alternative to lactulose in treatment of childhood constipation? Turk J Gastroenterol 2010;21:360-364.

23 Khoshoo V, Sun SS, Storm H: Tolerance of an enteral formula with insoluble and prebiotic fiber in children with compromised gastrointestinal function. J Am Diet Assoc 2010; 110:1728-1733.

24 Christensen MF: Recurrent abdominal pain and dietary fiber. Am J Dis Child 1986;140: 738-739.

25 Horvath A, Dziechciarz P, Szajewska H: Effectiveness of glucomannan in the treatment of abdominal pain-related functional gastrointestinal disorders in children: a randomized, double-blind, placebo-controlled trial. J Acad Nutr Diet Submitted.

26 Saad RJ: Peripherally acting therapies for the treatment of irritable bowel syndrome. Gastroenterol Clin North Am 2011;40:163-182.

27 de Vrese M, Schrezenmeir J: Probiotics, prebiotics, and synbiotics. Adv Biochem Eng Biotechnol 2008;111:1-66.

28 Gibson GR, Roberfroid MB: Dietary modulation of the human colonic microbiota: introducing the concept of prebiotics. J Nutr 1995;125:1401-1412.

29 Chmielewska A, Horvath A, Dziechciarz P, Szajewska H: Glucomannan is not effective for the treatment of functional constipation in children: a double-blind, placebo-controlled, randomized trial. Clin Nutr 2011;30: 462-468.

30 Roberfroid MB: Prebiotics: the concept revisited. J Nutr 2007;137:830S.

31 Spiller R: Review article: probiotics and prebiotics in irritable bowel syndrome. Aliment Pharmacol Ther 2008;28:385-396.

32 Carbohydrate and dietary fiber; in Kleinman RE (ed): Pediatric Nutrition Handbook, ed 4. Elk Grove Village, American Academy of Pediatrics, 1998, pp 203-211.

33 Williams CL, Bollella M, Wynder EL: A new recommendation for dietary fiber in childhood. Pediatrics 1995;96:985-988.

-34 Irvine EJ, Whitehead WE, Chey WD: Design of treatment trials for functional gastrointestinal disorders. Gastroenterology 2006;130: 1538-1551. 